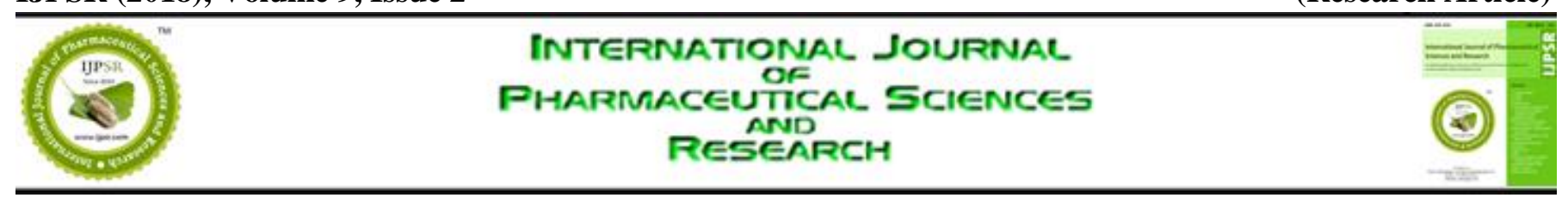

Received on 23 May, 2017; received in revised form, 04 August, 2017; accepted, 11 August, 2017; published 01 February, 2018

\title{
SYNTHESIS, CHARACTERIZATION AND BIOLOGICAL EVALUATION OF BENZIMIDAZOLE DERIVATIVES
}

\author{
Keshav Anand ${ }^{*}$ and Sharad Wakode
}

Department of Pharmaceutical Chemistry, Delhi Institute of Pharmaceutical Sciences and Research (DIPSAR), Sector - 3, Pushp Vihar, New Delhi - 110017, Delhi, India.

\section{Keywords:}

Benzimidazole,

Substituted Benzoic acid, Antimicrobial, Anti-fungal, Anti-oxidant

\section{Correspondence to Author: \\ Keshav Anand}

Research Scholar, Quarter No. 23/6, Railway Board Transit Quarter, Near Navy Children's School, Chankyapuri South - West Delhi, New Delhi - 110021, Delhi, India.

E-mail: keshavanandrai@gmail.com

\begin{abstract}
Benzimidazoles are an important class of compounds with a wide spectrum of biological activity ranging from anti-hypertensive, antiviral, anti-fungal, antitumor and anthelmintic activity. Benzimidazole rings are the most important nitrogen-containing heterocycles, which are widely explored and utilized by the pharmaceutical industry for drug discovery. Due to their special structural features and electron-rich environment, Benzimidazole containing drugs bind to a variety of therapeutic targets, thereby exhibiting a broad spectrum of bioactivities. Numerous benzimidazole based drugs have been extensively used in the clinic to treat various types of diseases with high therapeutic potential. A series of benzimidazole derivatives were synthesized by a single step process by reacting o-phenylenediamine and benzoic acid. The purity and structure confirmation of the synthesized compounds were done by TLC and ${ }^{1} \mathrm{H}$ NMR. The compounds were evaluated for anti-microbial, anti-fungal and antioxidant activity.
\end{abstract}

INTRODUCTION: Benzimidazole rings are the most important nitrogen-containing heterocycles, which are widely explored and utilized by the pharmaceutical industry for drug discovery ${ }^{1}$. Due to their special structural features and electron-rich environment, Benzimidazole containing drugs bind to a variety of therapeutic targets ${ }^{2}$, thereby exhibiting a broad spectrum of bioactivities. Numerous benzimidazole based drugs have been extensively used in the clinic to treat various types of diseases with high therapeutic potential ${ }^{3}$. Benzimidazole derivatives play important role in medical field with so many Pharmacological activities such as antimicrobial, antiviral, antidiabetic and anticancer activity ${ }^{3,4}$.

\begin{tabular}{|l|c|}
\hline QUICK RESPONSE CODE & DOI: \\
\hline DOI link: http://dx.doi.org/10.13040/IJPSR.0975-8232.9(2).617-24 \\
\hline
\end{tabular}

The potency of these clinically useful drugs in treatment of microbial infections and other activities encouraged the development of some more potent and significant compounds.

Benzimidazoles are remarkably effective compounds, extensive biochemical and pharmacological studies have confirmed that these molecules are effective against various strains of microorganisms ${ }^{5-7}$. Due to their enormous medicinal value, the research and development of benzimidazole-containing drugs is an increasingly active and attractive topic of medicinal chemistry. This review enlightens about the chemistry of different derivatives of substituted benzimidazoles along with their pharmacological activities ${ }^{8-11}$. Antimicrobial agents / Antibiotics are antibacterial substances produced by various species of micro-organism (bacteria, fungi, and actionomycetes) that suppress the growth of other micro-organisms. They have been designed to inhibit or kill the infecting organism without having measurable effect on the recipient ${ }^{4,7,11}$. 
Antioxidants are nutrients that help to protect cells from oxidative stress which is a natural damaging physiological process ${ }^{12}$. These nutrients are either present naturally in various types of food or taken as dietary supplements. They play defensive role against oxygen free radical toxicity in our body. Free radicals such as superoxide, hydroxyl and peroxide radicals are capable of damaging all types of biomolecules. They play vital role in causation and progress of oxidative stress related diseases such as Carcinogenesis, Alzheimer, Parkinson, Inflammatory diseases and Cataract. Thus, antioxidants may be considered as scavengers of free radicals. Reactive oxygen species (ROS) are formed when oxygen is present in excess and its reduction is insufficient. Natural occurring antioxidants are flavonoids, phenolic acid and alkaloids ${ }^{13}$.

The prepared compounds were subjected to physiochemical studies like melting point determination, TLC and percentage yield. The structures of synthesized compounds were characterized by IR and NMR spectroscopy 14,15 . The biological evaluation of newly synthesized compounds was carried out against E. coli and Staphylococcus aureus for antibacterial screening. The other in vitro activities carried out were antiinflammatory and antioxidant activity. Benzimidazoles mainly possess various types of biological activities like anti-inflammatory, anticancer, anti-fungal, antiviral and anthelmintic activity etc. The Benzimidazole derivatives have been the center of the attention of researchers over many years due to high practical value of these compounds ${ }^{16-26}$.

\section{MATERIALS AND METHODS:}

Chemistry: Nuclear Magnetic Resonance $\left({ }^{1} \mathrm{H}-\right.$ NMR) spectra were recorded on a Bruker using $\mathrm{CDCl}_{3}$. The Chemical shift values are reported in parts per million (ppm) relative to Tetra methyl silane as internal reference. Infra-red (IR) spectra were recorded with a Bruker spectrophotometer. The melting point ranges of newly synthesized compounds were determined by open glass capillary tube using Lab India's visual melting point apparatus and were uncorrected. All the commercially available reagent grade chemicals were used as received. Purity of the compound and progress of the reaction were monitored by thin layer chromatography (TLC), with detection by Ultra-violet (UV) light and / or spots were visualized by exposure to iodine vapors ${ }^{27}$.

Synthesis: The title compounds were synthesized using synthetic strategy described in Fig. ${ }^{28}$. Benzimidazole compounds were synthesized starting from o-phenylenediamine and benzoic acid.

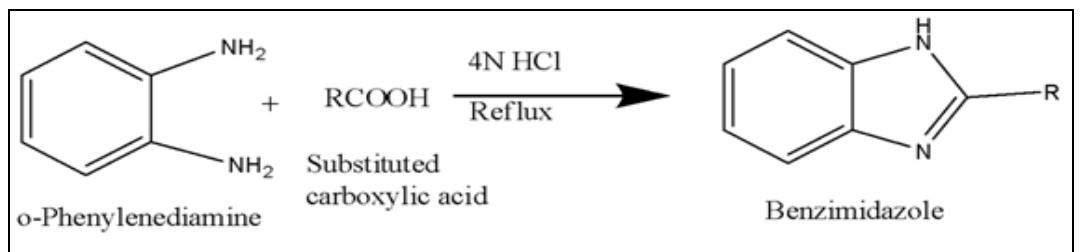

FIG. 1: SYNTHESIS OF BENZIMIDAZOLE DERVATIVES

Substituted carboxylic acid: Formic acid, Benzoic acid, 2-amino benzoic acid, 3, 4-dimethoxybenzoic acid, 3, 4, 5trimethoxybenzoic acid, 2-chloro-4-nitro benzoic acid, 2-chloro-5-nitro benzoic acid, 2- Iodo benzoic acid, 4-methoxyphenyl acetic acid, 4-ethyl benzoic acid, 2, 4, 5-trifluoro benzoic acid, 4-chloro-3, 5-dinitro benzoic acid

Mechanism of Reaction: The role of hydrochloric The reaction mechanism involves carbonium ion acid is to activate carboxyl group by addition of a intermediate. proton to oxygen, forming carbonium ion.

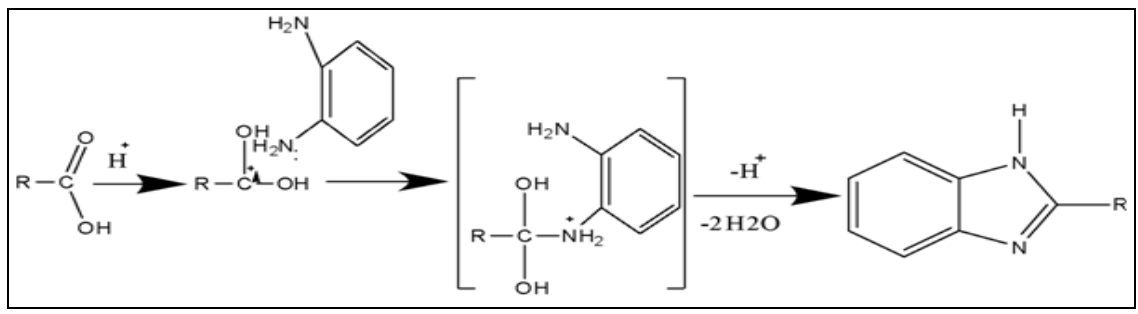


General Procedure for Synthesis of Title Compound (1a-l): O-phenylenediamine (0.01 mole) was refluxed with formic acid, benzoic acid and its derivatives $(0.01$ mole $)$ in the presence of $4 \mathrm{~N}$ hydrochloric acid $(4 \mathrm{~N} \mathrm{HCl})$ for $4-5 \mathrm{hrs}$ at temperature $80-120{ }^{\circ} \mathrm{C}$, rpm 320 on reflux condenser. The completion of the reaction was checked by TLC (chloroform: methanol 9:1). On completion, $10 \% \mathrm{NaOH}(\mathrm{w} / \mathrm{v})$ was gradually added until the reaction mixture turns alkaline. Reaction mixture was cooled in ice bath, allowed to stand for 5 min to obtain precipitate. The product was is filtered, dried and recrystallized from ethanol ${ }^{14,27,28}$.

CSK - 0:1 H- Benzimidazole (1.a): Yield 64\%, M.P.170-173 ${ }^{\circ} \mathrm{C}$; ATR: N-H $\left(3512.89 \mathrm{~cm}^{-1}\right), \mathrm{C}=\mathrm{C}$ $\left(1510.45,1454 \mathrm{~cm}^{-1}\right), \mathrm{C}=\mathrm{N}\left(1665.55 \mathrm{~cm}^{-1}\right)$.

${ }^{1} \mathrm{HNMR}$ (DMSO, 300MHz): $\delta 5.00$ (s, 2H NH), 7.26 (dd, 2H, Ar-H), 7.70 (dd, 2H, Ar-H), 8.08 (s, $1 \mathrm{H}, \mathrm{Ar}-\mathrm{H})$.

CSK-00:2-Phenyl-1H-Benzimidazole (1.b): Yield $66 \%$, M.P. $293-296{ }^{\circ}$ C; ATR: N-H $\left(3529.43 \mathrm{~cm}^{-1}\right)$, $\mathrm{C}=\mathrm{C}\left(1443.83,1409.39 \mathrm{~cm}^{-1}\right), \mathrm{C}=\mathrm{N}(1569.57$ $\left.\mathrm{cm}^{-1}\right)$.

${ }^{1} \mathrm{HNMR}$ (DMSO, 300MHz): $85.00(\mathrm{~s}, 1 \mathrm{H} \mathrm{NH})$, 7.24 (dd, 2H, Ar-H), 7.54-7.46 (m, 3H, Ar-H), 7.66 (dd, 2H), 8.39-8.31 (m, 2H, Ar-H).

CSK- 1: 2- (1H- 1, 3- zbenzodiazol- 2- yl) aniline (1.c): Yield 77\%, M.P. 224 - $226{ }^{\circ} \mathrm{C}$; ATR: N-H $\left(3354.70 \mathrm{~cm}^{-1}\right), \mathrm{C}=\mathrm{C}\left(1289.25,1351.07 \mathrm{~cm}^{-1}\right), \mathrm{C}=$ $\mathrm{N}\left(1701.08 \mathrm{~cm}^{-1}\right)$.

${ }^{1} \mathrm{HNMR}$ (DMSO, 300MHz): $\delta 6.72(1 \mathrm{H}, \mathrm{ddd}, \mathrm{Ar}-$ H), 7.15-7.25 (3H, 7.15 (ddd, Ar-H Benz), 7.23 (ddd, Ar-H Benz), 7.39 (ddd, Ar-H)), $7.49 \quad(1 \mathrm{H}$, ddd, $A r-H$ ), 7.57-7.58 (2H, 7.57 (ddd, Ar-H), 7.58 (ddd, Ar-H Benz)).

CSK- 2: 2- (3, 4- dimethoxyphenyl)- 1H- 1, 3benzodiazole (1.d): Yield $70 \%$, M.P. $234-237{ }^{\circ} \mathrm{C}$; ATR: $\mathrm{N}-\mathrm{H}\left(3547.86 \mathrm{~cm}^{-1}\right), \mathrm{C}=\mathrm{C}$ (1514.94, $\left.1465.30 \mathrm{~cm}^{-1}\right), \mathrm{C}=\mathrm{N}\left(1675.17 \mathrm{~cm}^{1}\right)$, Asymmetric C-O-C (1265.64 cm $\left.\mathrm{cm}^{-1}\right)$, Symmetric C-O-C (1134.19 $\left.\mathrm{cm}^{-1}\right)$, Aromatic C-H stretch $\left(3360.64 \mathrm{~cm}^{-1}\right)$, Out of plane ring C-O blend $\left(627.52 \mathrm{~cm}^{-1}\right)$, Out of plane C$\mathrm{H}$ bend $\left(723.04,761.76 \mathrm{~cm}^{-1}\right)$.

${ }^{1} \mathrm{HNMR}$ (DMSO, 300MHz): $\delta 3.83$ (3H, 3.83 (s), 3.83 (s), 3.83 (s)), 3.83 (3H, 3.83 (s), 3.83 (s), 3.83 (s)), $6.99(1 \mathrm{H}, \mathrm{dd}, A r-H), 7.22(1 \mathrm{H}, \mathrm{ddd}, A r-H)$, 7.25-7.28 (2H, 7.25 (dd, Ar-H), 7.28 (ddd, Ar-H)), $7.54(1 \mathrm{H}, \mathrm{dd}, A r-H), 7.59(1 \mathrm{H}, \mathrm{ddd}, A r-H), 7.60$ (1H, ddd, Ar-H).

CSK- 3: 2- (3, 4, 5- trimethoxyphenyl)- 1H- 1, 3benzodiazole (1.e): Yield 83\%, M.P. 206 - $208{ }^{\circ} \mathrm{C}$; ATR: N-H (3381.28 cm $\left.\mathrm{cm}^{-1}\right), \mathrm{C}=\mathrm{C}\left(1415.25 \mathrm{~cm}^{-1}\right), \mathrm{C}$ $=\mathrm{N}\left(1678.94 \mathrm{~cm}^{-1}\right)$, Asymmetric C-O-C (1227.43 $\left.\mathrm{cm}^{-1}\right)$, Symmetric C-O-C $\left(1183.41 \mathrm{~cm}^{-1}\right)$, Out of plane ring $\mathrm{C}-\mathrm{O}$ blend $\left(710.92 \mathrm{~cm}^{-1}\right)$, Out of plane $\mathrm{C}-\mathrm{H}$ bend $\left(752.85 \mathrm{~cm}^{-1}\right)$.

${ }^{1} \mathrm{HNMR}$ (DMSO, 300MHz): $\delta 3.83$ (9H, 3.83 (s), $3.83(\mathrm{~s}), 3.83$ (s), 3.83 (s), 3.83 (s), 3.83 (s), 3.83 (s), 3.83 (s), $\left.3.83(\mathrm{~s}), \mathrm{O}-\mathrm{CH}_{3}\right), 6.94-7.24(3 \mathrm{H}, 6.94$ (s), 6.94 (s), 7.24 (ddd, Ar-H)), 7.26 (1H, ddd, Ar$H), 7.57$ (1H, ddd, Ar-H), 7.58 (1H, ddd, Ar-H).

CSK- 4: 2- (2- chloro- 4- nitrophenyl)- 1H- 1, 3benzodiazole (1.f): Yield 74\%, M.P. 185 - $188{ }^{\circ} \mathrm{C}$; ATR: NH $\left(3405.85 \mathrm{~cm}^{-1}\right)$, Aromatic C-H stretch $\left(3466.92 \mathrm{~cm}^{-1}\right)$, Out of plane $\mathrm{C}-\mathrm{H}$ bend $(851.48$, $\left.897.55 \mathrm{~cm}^{-1}\right)$, Aromatic C $=\mathrm{C}\left(1594.67 \mathrm{~cm}^{-1}\right)$, Ortho substitution $\left(738.05 \mathrm{~cm}^{-1}\right), \mathrm{C}-\mathrm{Cl}(802.63$ $\left.\mathrm{cm}^{-1}\right) \mathrm{NO}_{2}\left(1520.29,1475.77 \mathrm{~cm}^{-1}\right)$.

${ }^{1} \mathrm{HNMR}$ (300MHz, DMSO): ${ }^{1} \mathrm{H}$ NMR: $\delta 7.26(1 \mathrm{H}$, td, Ar-H Benz), 7.60 (1H, ddd, Ar-H Benz), 7.61 (1H, ddd, Ar-H Benz), 7.62 (1H, ddd, Ar-H Benz.), 7.81-8.21 (2H, 7.81 (dd, Ar-H), 8.21 (dd, Ar-H)), $8.39(1 \mathrm{H}, \mathrm{dd}, A r-H)$.

CSK- 5: 2- (2- chloro- 5- nitrophenyl)- 1H- 1, 3benzodiazole (1.g): Yield 60\%, M.P. $211-214{ }^{\circ} \mathrm{C}$; ATR: $\mathrm{NH}\left(3446.35 \mathrm{~cm}^{-1}\right)$, Aromatic $\mathrm{C}=\mathrm{C}$ (1612.28 cm-1), C-N, C - C bend (1575.25, $\left.1418.77 \mathrm{~cm}^{-1}\right)$, Ortho substitution $\left(734.82 \mathrm{~cm}^{-1}\right), \mathrm{C}$ $\mathrm{Cl}\left(846.12 \mathrm{~cm}^{-1}\right), \quad A r-\mathrm{NO}_{2}$ Asymmetric and Symmetric $\left(1534.00,1352.62 \mathrm{~cm}^{-1}\right)$.

${ }^{1} \mathrm{H}$ NMR (300MHz, DMSO): $\delta$ 7.23-7.30 (2H, 7.23 (ddd, Ar-H Benz), 7.30 (ddd, Ar-H Benz)), 7.57 (1H, ddd, Ar-H Benz), 7.71 (1H, dd, Ar-H), 8.16 (1H, ddd, Ar-H Benz), 8.42 (1H, dd, Ar-H), 8.50 $(1 \mathrm{H}, \mathrm{dd}, A r-H)$.

CSK- 6: 2- (2-iodophenyl)-1H-1, 3-benzodiazole (1.h): Yield 68\%, M.P. 235 - $237{ }^{\circ} \mathrm{C}$; ATR: NH (3344.11 $\left.\mathrm{cm}^{-1}\right), \mathrm{CH}_{2}\left(2892.74 \mathrm{~cm}^{-1}\right)$, Ar $\mathrm{C}=\mathrm{C}$ (1579.43, cm-1), $\mathrm{CH}_{2} \mathrm{I}$ bend $\left(1263.17 \mathrm{~cm}^{-1}\right)$, ortho substitution $\left(735.82 \mathrm{~cm}^{-1}\right), \mathrm{R}-\mathrm{I}\left(<600.00 \mathrm{~cm}^{-1}\right)$. 
${ }^{1} \mathrm{H}$ NMR (300 MHz, DMSO): $\delta$ 7.10-7.30 (2H, 7.10 (ddd, Ar-H Benz), 7.25 (ddd, Ar-H Benz)), 7.38 (1H, ddd, $A r-H), 7.50-7.58$ (2H, 7.50 (ddd, $A r-$ $H), 7.58$ (ddd, $A r-H)$ ), 7.63 (1H, ddd, Ar-H), 7.817.84 (2H, 7.81 (ddd, Ar-H Benz), 7.84 (ddd, Ar-H Benz)).

CSK- 7: 2- benzyl-1H-1, 3- benzodiazole (1.i): Yield 75\%, M.P. 275 - $278{ }^{\circ} \mathrm{C}$; ATR: $\mathrm{NH}_{2}$ (3443.09 $\left.\mathrm{cm}^{-1}\right), \mathrm{CH}_{2}\left(2978.21,2884.09 \mathrm{~cm}^{-1}\right), \mathrm{Ar} \mathrm{C}$ $=\mathrm{C}\left(1610.06, \mathrm{~cm}^{-1}\right), \mathrm{CH}_{2}$ bend $\left(1441.28 \mathrm{~cm}^{-1}\right)$. ${ }^{1} \mathrm{HNMR}$ (300MHz, DMSO): $\delta 4.08$ (2H, 4.08 (s), 4.08 (s), - $\mathrm{CH}_{2}$ ), 6.62 (1H, ddd, Ar-H Benz), 7.19 (1H, ddd, Ar-H Benz), 7.21-7.26 (5H, 7.25 (tt, Ar$H), \quad 7.21 \quad$ (ddd, Ar-H), $7.21 \quad$ (ddd, Ar-H), 7.26 (td, $A r-H), 7.26$ (td, $A r-H)$ ), 7.53-7.57 (2H, 7.53 (ddd, Ar-H Benz), 7.57 (ddd, Ar-H Benz)).

CSK- 8: 2-(4-ethylphenyl)-1H-1, 3-benzodiazole (1.j): Yield 55\%, M.P. 192 - $195{ }^{\circ} \mathrm{C}$; ATR: $\mathrm{NH}_{2}$ $\left(3380.33 \mathrm{~cm}^{-1}\right), \mathrm{CH}_{2}\left(2991.06,2718.76 \mathrm{~cm}^{-1}\right), \operatorname{Ar~C}$ $=\mathrm{C}\left(1603.00 \mathrm{~cm}^{-1}\right), \mathrm{CH}_{2}$ bend $\left(1475.96 \mathrm{~cm}^{-1}\right)$, para substitution $\left(753.89 \mathrm{~cm}^{-1}\right)$.

${ }^{1} \mathrm{HNMR}(300 \mathrm{MHz}, \mathrm{DMSO}): \delta 1.31(3 \mathrm{H}, 1.31(\mathrm{t},-$ $\left.\left.\mathrm{CH}_{3}\right), 1.31\left(\mathrm{t},-\mathrm{CH}_{3}\right), 1.31\left(\mathrm{t},-\mathrm{CH}_{3}\right)\right), 2.64(2 \mathrm{H}, 2.64$ $\left.\left(\mathrm{q},-\mathrm{CH}_{2}\right), 2.64\left(\mathrm{q},-\mathrm{CH}_{2}\right)\right), 7.24-7.27(2 \mathrm{H}, 7.24$ (dd, Ar-H Benz), 7.27 (dd, Ar-H Benz)), 7.33 (2H, 7.33 (dd, $A r-H), 7.33$ (dd, $A r-H)$ ), 7.58 (2H, 7.58 (dd, $A r-H), 7.58$ (dd, Ar-H)), 7.62 (1H, ddd, $A r-H$ Benz), 7.62 (1H, ddd, Ar-H Benz)

CSK- 9: 2- (2, 4, 5-trifluorophenyl)-1H-1, 3benzodiazole (1.k): Yield $60 \%$, M.P. $182-184{ }^{\circ} \mathrm{C}$; ATR: $\mathrm{NH}\left(3398.54 \mathrm{~cm}^{-1}\right), \mathrm{CH}_{2}(2918.94,2851.71$ $\left.\mathrm{cm}^{-1}\right), \mathrm{Ar} \mathrm{C}=\mathrm{C}(1475.22 \mathrm{~cm}-1), \mathrm{CH}_{2}$ bend $\left(1462.98 \mathrm{~cm}^{-1}\right)$, para substitution $\left(827.88 \mathrm{~cm}^{-1}\right)$.

${ }^{1} \mathrm{HNMR}:(300 \mathrm{MHz}, \mathrm{DMSO}): \delta 6.96-7.25$ (2H, 7.24 (d, Ar-H), 7.25 (td, Ar-H Benz)), 7.35 (1H, ddd, ArH Benz), 7.56-7.58 (2H, 7.56 (ddd, Ar-H Benz), 7.58 (ddd, Ar-H Benz)), 7.58 (1H, d, Ar-H).

CSK- 10: 2- (4-chloro-3, 5-dinitrophenyl)-1H-1, 3-benzodiazole (1.l): Yield 62\%, M.P. $161-163{ }^{\circ} \mathrm{C}$; ATR: NH (3460.10, $\left.3350.45 \mathrm{~cm}^{-1}\right), \mathrm{CH}_{2}$ (2924.67, $\left.2853.51 \mathrm{~cm}^{-1}\right), \operatorname{Ar~C}=\mathrm{C}(1475.11 \mathrm{~cm}-1), \mathrm{CH}_{2}$ bend $\left(1463.55 \mathrm{~cm}^{-1}\right)$, para substitution $\left(799.85 \mathrm{~cm}^{-1}\right)$.

${ }^{1} \mathrm{HNMR}$ (300MHz, DMSO): $\delta 5.80(\mathrm{~s}, 1 \mathrm{H}, \mathrm{NH})$, 7.27 (1H, ddd, Ar-H Benz), 7.58 (1H, ddd, Ar-H Benz), 7.61-7.63 (2H, 7.61 (ddd, Ar-H Benz), 7.63 (ddd, Ar-H Benz)), 8.80 (2H, 8.80 (s), 8.80 (s) Ar$H)$.

Pharmacological Evaluation: ${ }^{16-25,29-34}$

Antimicrobial Activity: All synthesised compounds were screened for in vitro antibacterial activity against one gram positive strain of bacteria $(S$. aureus) and one gram negative strain of bacteria (E. coli) by cup plate method. Cefodoxamine was used as reference antibacterial drug ${ }^{19,20,33}$.

Cup Plate Method: The nutrient agar medium was prepared by dissolving commercially available agar in distilled water. Immediately it was then autoclaved and cooled to $45-50{ }^{\circ} \mathrm{C}$. The nutrient agar medium was inoculated aseptically with $0.5 \mathrm{ml}$ of strains of $S$. aureus and $E$. coli at room temperature. Into each sterile Petri dish about $15 \mathrm{ml}$ of inoculated molten agar medium was poured. The plates were left at room temperature for solidification. After solidification, the cups of $6 \mathrm{~mm}$ diameter Petri dish and were made by scooping out the medium with the sterilized corn borer from Petri dish and were labeled. All the synthesized compounds and reference were dissolved in DMSO to prepare appropriate dilution to get required concentration of $25 \mu \mathrm{g} / \mathrm{ml}, 50 \mu \mathrm{g} / \mathrm{ml}$ and $100 \mu \mathrm{g} / \mathrm{ml}$. The solutions of each compound, reference and a control (DMSO) were added separately into each cups. The plates were kept undisturbed for about 24 hours at room temperature. After incubation period of 24 hours the diameter of zone of inhibition was measured with the help of antibiotic zone reader. The results are presented in Table $\mathbf{1}$ and Table 2.

TABLE 1: ANTIBACTERIAL ACTIVITY OF COMPOUNDS AGAINST $S$. AUREUS GRAM POSITIVE BACTERIA (S. AUREUS)

\begin{tabular}{cccc}
\hline & Zone of Inhibition $(\mathbf{m m})$ \\
\hline Conc. & $\mathbf{2 5}$ & $\mathbf{5 0}$ & $\mathbf{1 0 0}$ \\
\hline CSK-0 & 6 & 9 & 13 \\
CSK-00 & 8 & 11 & 14 \\
CSK-1 & 6 & 10 & 13 \\
CSK-2 & 9 & 17 & 19 \\
CSK-3 & 7 & 15 & 20 \\
CSK-4 & 10 & 13 & 15 \\
CSK-5 & 10 & 14 & 17 \\
CSK-6 & 6 & 11 & 15 \\
CSK-7 & 13 & 16 & 19 \\
CSK-8 & 10 & 14 & 18 \\
CSK-9 & 13 & 18 & 21 \\
CSK-10 & 12 & 16 & 20 \\
Standard & 16 & 20 & 23 \\
& & & \\
\hline
\end{tabular}


TABLE 2: ANTIBACTERIAL ACTIVITY OF COMPOUNDS AGAINST E. COLI, GRAM NEGATIVE BACTERIA (E. COLI)

\begin{tabular}{cccc}
\hline & \multicolumn{3}{c}{ Zone of Inhibition $(\mathbf{m m})$} \\
\hline Concentration & $\mathbf{2 5}$ & $\mathbf{5 0}$ & $\mathbf{1 0 0}$ \\
\hline CSK-0 & 20 & 23 & 24 \\
CSK-00 & 19 & 22 & 24 \\
CSK-1 & 21 & 24 & 26 \\
CSK-2 & 18 & 21 & 23 \\
CSK-3 & 11 & 16 & 21 \\
CSK-4 & 25 & 27 & 33 \\
CSK-5 & 12 & 18 & 20 \\
CSK-6 & 19 & 21 & 25 \\
CSK-7 & 13 & 19 & 23 \\
CSK-8 & 12 & 17 & 19 \\
CSK-9 & 23 & 25 & 30 \\
CSK-10 & 22 & 25 & 29 \\
Standard & 28 & 30 & 35 \\
\hline
\end{tabular}

Antioxidant Activity: ${ }^{17-19,34}$

DPPH (2-diphenyl-1-picryl-hydrazyl) RadicalScavenging Assay: Various concentrations of synthesized compound $(20 \mu \mathrm{g} / \mathrm{ml}, 40 \mu \mathrm{g} / \mathrm{ml}, 60 \mu \mathrm{g} / \mathrm{ml}$, $80 \mu \mathrm{g} / \mathrm{ml}$ and $100 \mu \mathrm{g} / \mathrm{ml}$ ) were prepared by dissolving in DMSO. To this solution, $1 \mathrm{ml}$ of freshly prepared $0.1 \mathrm{mM}$ methanolic solution of DPPH was added. It was then kept in dark for 30 min. The absorbance was measured at $517 \mathrm{~nm}$. DMSO was used as blank and Ascorbic acid was used as standard. The capability to scavenge the DPPH radical was calculated using the following equation and results of DPPH activity are presented in Table 3.

DPPH scavenged $(\%)=\left(\mathrm{A}_{\text {control }}-\mathrm{A}_{\text {test }}\right) \mathrm{X} 100 / \mathrm{A}_{\text {control }}$

Where, $\mathrm{A}_{\text {control }}$ was the absorbance of DPPH + methanol, and $\mathrm{A}_{\text {test }}$ was the absorbance of DPPH + sample / standard.

TABLE 3: DPPH ASSAY RESULTS

\begin{tabular}{ccccc}
\hline S. no. & Compound & \multicolumn{3}{c}{ Percentage Inhibition (\%) } \\
\hline & & $\mathbf{2 0 u g} / \mathbf{m l}$ & $\mathbf{6 0 u g} / \mathbf{m l}$ & $\mathbf{1 0 0 u g} / \mathbf{m l}$ \\
\hline 1. & CSK-0 & 1.92 & 3.58 & 7.77 \\
2. & CSK-00 & 4.97 & 12.88 & 23.13 \\
3. & CSK-1 & 20.15 & 44.23 & 66.15 \\
4. & CSK-2 & 7.15 & 21.43 & 40.07 \\
5. & CSK-3 & 6.22 & 8.39 & 12.43 \\
6. & CSK-4 & 4.32 & 9.94 & 17.11 \\
7. & CSK-5 & 27.02 & 44.73 & 55.28 \\
8. & CSK-6 & 33.86 & 52.18 & 72.05 \\
9. & CSK-7 & 27.64 & 31.7 & 36.03 \\
10. & CSK-8 & 3.97 & 7.18 & 11.63 \\
11. & CSK-9 & 30.05 & 56.78 & 78.09 \\
12. & CSK-10 & 20.91 & 39.94 & 68.4 \\
13. & Ascorbic Acid & 30.75 & 57.4 & 80.84 \\
\hline
\end{tabular}

ABTS (2, 2'-azino-bis (3-ethylbenzthiazoline-6sulfonic acid) Radical Scavenging Assay: This assay is based on the ability of different compounds to scavenge 2, 2-azino-bis (ethylbenzthizoline-6sulfonic acid) radical cation. ABTS radicals have characteristic absorbance at $734 \mathrm{~nm}$. This absorbance decreases when radical is reduced by any antiradical compound. The decrease in the absorbance can be measured using UV-VIS spectrophotometer at $734 \mathrm{~nm}$. For ABTS assay, the stock solutions of
$7 \mathrm{mM}$ ABTS and $2.4 \mathrm{mM}$ potassium persulfate were prepared. The working solution was then prepared by mixing the two stock solutions in equal quantities (1:1) and allowing them to react for $12 \mathrm{~h}$ at room temperature in the dark.

The solution (1ml) was then diluted with $60 \mathrm{ml}$ methanol to obtain an absorbance of $0.706 \pm 0.001$ units at $734 \mathrm{~nm}$ using the UV spectrophotometer. Methanolic solutions of all compounds as well as 
ascorbic acid were prepared in the concentration of $20 \mathrm{ug} / \mathrm{ml}, 40 \mathrm{ug} / \mathrm{ml}, 60 \mathrm{ug} / \mathrm{ml}, 80 \mathrm{ug} / \mathrm{ml}$ and $100 \mathrm{ug} / \mathrm{ml}$. Compounds / Ascorbic acid (1ml) of different concentration was allowed to react with $1 \mathrm{ml}$ of the $\mathrm{ABTS}^{+}$solution and the absorbance was taken at $734 \mathrm{~nm}$ using UV spectrophotometer. The $\mathrm{ABTS}^{+}$ scavenging capacity of the extract was compared with that of Ascorbic acid and percentage inhibition calculated using the following equation and results of ABTS activity are presented in Table 4.

ABTS radical scavenging activity $(\%)=\mathrm{Abs}_{\text {control }}-$ $\mathrm{Abs}_{\text {sample }} / \mathrm{Abs}_{\text {control }} \times 100$

Where, $\mathrm{Abs}_{\text {control }}$ was the absorbance of ABTS radical + methanol, and $\mathrm{Abs}_{\text {sample }}$ was the absorbance of ABTS radical + sample / standard.

TABLE 4: ABTS ASSAY RESULTS

\begin{tabular}{ccccc}
\hline S. no. & Compound & \multicolumn{3}{c}{ Percentage Inhibition (\%) } \\
\hline & & $\mathbf{2 0 u g} / \mathbf{m l}$ & $\mathbf{6 0 u g} / \mathbf{m l}$ & $\mathbf{1 0 0 u g} / \mathbf{m l}$ \\
\hline 1. & CSK-0 & 1.04 & 2.3 & 6.03 \\
2. & CSK-00 & 16.97 & 34.03 & 44.96 \\
3. & CSK-1 & 23.3 & 39.75 & 69.15 \\
4. & CSK-2 & 7.4 & 22.44 & 31.74 \\
5. & CSK-3 & 6.98 & 19.57 & 32.84 \\
6. & CSK-4 & 0.9 & 2.88 & 6.98 \\
7. & CSK-5 & 22.44 & 48.6 & 51.44 \\
8. & CSK-6 & 30.64 & 46.65 & 70.05 \\
9. & CSK-7 & 24.22 & 30.37 & 39.25 \\
10. & CSK-8 & 5.64 & 18.63 & 25.43 \\
11. & CSK-9 & 19.6 & 40.32 & 67.05 \\
12. & CSK-10 & 13.3 & 24.08 & 31.2 \\
13. & Ascorbic Acid & 30.88 & 57.6 & 80.86 \\
\hline
\end{tabular}

\section{Antifungal Activty 21, 27, 28,31}

Introduction: Antifungal is also the most widely studied group of antimicrobials. Antifungal is the agent that either kills or inhibits the growth of fungi. It is used in the treatment and prevention of fungal infections. All synthesized compounds were screened for in vitro antifungal activity against Candida albicans strain of fungi by disc diffusion method. Fluconazole was used as reference antifungal drug.

Paper Disc Diffusion Method: The Sabouroud Dextrose agar was prepared by dissolving in distilled water. Its $\mathrm{pH}$ was adjusted and immediately it was then autoclaved and cooled to $45-50{ }^{\circ} \mathrm{C}$. Into each sterile petridish about $15 \mathrm{ml}$ of molten Sabouroud medium was poured. The Sabouroud agar medium was inoculated aseptically by streaking with strain of Candida albicans at room temperature. The plates were left at room temperature for solidification.

All the synthesized compounds and reference were dissolved in DMSO to prepare appropriate dilution to get required concentration of $10 \mu \mathrm{g} / \mathrm{ml}, 25 \mu \mathrm{g} / \mathrm{ml}$, $50 \mu \mathrm{g} / \mathrm{ml}$ and $100 \mu \mathrm{g} / \mathrm{ml}$ and were coated on separate sterile filter paper discs (What man No. 1) measuring $6 \mathrm{~mm}$ in size. The discs were then placed on the surface of solidified Sabouroud medium of each inoculated Petri dishes. DMSO used as negative control, while fluconazole were used as positive control for obtaining comparative results.

All treated and untreated plates were incubated for $48 \mathrm{~h}$ at $37^{\circ} \mathrm{C}$. After incubation period of 48 hours the diameter of zone of inhibition was measured with the help of antibiotic zone reader or simple scale. The results are presented in Table 5.

TABLE 5: ANTIFUNGAL ACTIVITY OF COMPOUNDS AGAINST CANDIDA ALBICANS

\begin{tabular}{cccccc}
\hline & \multicolumn{5}{c}{ Candida albicans } \\
\hline S. No. & Compounds & \multicolumn{4}{c}{ Zone of Inhibition (in $\mathbf{~ m m})$} \\
\cline { 2 - 6 } & & $\mathbf{1 0 u g} / \mathbf{m l}$ & $\mathbf{2 5} \mathbf{u g} / \mathbf{m l}$ & $\mathbf{5 0 u g} / \mathbf{m l}$ & $\mathbf{1 0 0 u g} / \mathbf{m l}$ \\
\hline 1. & CSK-0 & - & - & 8 & 16 \\
2. & CSK-00 & - & 12 & 16 & 20 \\
3. & CSK-1 & 6 & 14 & 18 & 22 \\
4. & CSK-2 & - & 6 & 10 & 18 \\
5. & CSK-3 & 4 & 8 & 14 & 20 \\
\hline
\end{tabular}




\begin{tabular}{rrcccc}
\hline 6. & CSK-4 & 10 & 16 & 20 & 26 \\
7. & CSK-5 & 8 & 14 & 18 & 22 \\
8. & CSK-6 & 8 & 16 & 18 & 24 \\
9. & CSK-7 & - & - & 6 & 16 \\
10. & CSK-8 & 10 & 18 & 22 & 28 \\
11. & CSK-9 & - & 15 & 19 & 24 \\
12. & CSK-10 & - & 9 & 15 & 22 \\
13. & Fluconazole & 15 & 20 & 26 & 30 \\
\hline
\end{tabular}

RESULTS AND DISCUSSION: A series of Benzimidazole derivatives were synthesized, characterized and evaluated for antibacterial, antifungal and anti-oxidant activities. The compounds were synthesized in moderate to good yield. Purity of compounds was determined by TLC on silica gel G plates. The spots were detected by exposure to iodine vapors. Synthesized compounds were characterized by spectral analysis (Fourier Transform Infra-red and ${ }^{1}$ HNMR.

Antibacterial Activity: All the synthesized compounds were evaluated for their in vitro antibacterial activity and results are depicted in Table 1 and 2. It was found that compound CSK-3, CSK-4, CSK-9 and CSK-10 are comparatively more active than all other compounds against gram positive strain of bacteria ( $S$. aureus) and gram negative strain of bacteria (E. coli).

Antioxidant Activity: Antioxidant activity was measured by DPPH and ABTS assay method and compound CSK-6 and CSK-9 showed best Scavenging activity at concentration of 40, 60, 80 and $100 \mu \mathrm{g} / \mathrm{ml}$, when compared with ascorbic acid as standard. Other compounds with good antioxidant activity are CSK-1, CSK-5 and CSK10. Although, all compounds show appreciable amount of antioxidant activity and results are depicted in Table 3 and 4.

Antifungal Activity: All the synthesized compounds were evaluated for their in vitro antifungal activity and results are depicted in Table 5. It is found that compound CSK-8, CSK-4, CSK-6 and CSK-9 are comparatively more active than all other compounds against Candida albicans.

CONCLUSION: A series of Benzimidazole derivatives were synthesised and screened for biological activity. In summary, all the derivatives showed promising Antibacterial, Antioxidant and Antifungal activity when compared with that of standard.
The diverse aspects clearly show the high potential of Benzimidazole derivatives and the relevance and importance of research done with these compounds. This work will hopefully be used for further development of potential inhibitor drugs.

ACKNOWLEDGEMENT: Authors are thankful to the Delhi Institute of Pharmaceutical Sciences and research (DIPSAR), University of Delhi (DU), DPSR - University for providing laboratory facilities, instruments, chemicals and IR analysis. We are also thankful to Jamia Hamdard, New Delhi for analyzing the NMR Spectral data. Authors are also thankful for providing cooperation, help and moral support of Avneet Kaur, Hitesh Kumar, Faizana Jargar, Shubham Pratap Singh, Uma kumar and Md. Sarfaraz.

CONFLICTS OF INTEREST: The authors declare no conflict of interest.

\section{REFERENCES:}

1. Abraham D and Burger A: Burger's medicinal chemistry and drug discovery, $6^{\text {th }}$ ed. Hoboken NJ: Wiley 2003; 113 120.

2. Patrick L: An Introduction to Medicinal Chemistry. $4^{\text {th }}$ ed. Oxford 2009; 152-153.

3. Lemke T, Williams D, Roche V and Zito S: Foye's Principles of Medicinal Chemistry. $7^{\text {th }}$ ed. Lippincott Williams and Wilkins 2008.

4. Rang $\mathrm{H}$ and Dale M: Rang and Dale's pharmacology. $7^{\text {th }}$ ed. Edinburgh: Elsevier / Churchill Livingstone 2012.

5. Bansal R: Heterocyclic chemistry. $4^{\text {th }}$ ed. Tunbridge Wells: Anshan Ltd., 2007; 1-2.

6. Santosh P, Pandeya S and Pathak A: Benzimidazole: A Versatile Chemical Entity. IJRAP 2011; 2(6): 1726-1737.

7. Rehman M: Mannich base derivatives of Benzimidazole: synthesis and antimicrobial properties. WAP 2013; 3: 558564.

8. Fatmah et al.: Synthesis and Evaluation of Selected Benzimidazole Derivatives as Potential Antimicrobial Agents, Molecules 2015; 20: 15206-15223. Doi: 10.3390/ molecules200815206.

9. Kalyankar T: Review on Benzimidazole derivative. International Journal of Chemical and Pharmaceutical Sciences 2012; 3(4): 1-8

10. Bala S, Sharma N, Kajal A, Kamboj S and Saini V: Mannich Bases: An Important Pharmacophore in Present Scenario. International Journal of Medicinal Chemistry 2014; 1-15. 
11. Kalidhar U, Kumar R and Kaur A: Synthesis, Spectral Studies and Biological Evaluation of Some Benz imidazole Derivatives containing Sulfonamide. Research Journal of Pharmaceutical, Biological and Chemical Sciences 2012; 3(2): 1074.

12. Kamil A, Akhtar S, Jahan S, Karim A, Rafiq K and Hassan S: Benzimidazole Derivatives: Active Class of Antioxidants. International Journal of Scientific and Engineering Research 2013; 4(8): 1674-1685.

13. Sumayya K: Synthesis, characterization and antioxidation studies of 2-benzylthiobenzimidazole derivatives. Indian journal of chemistry and pharmaceutical research 2013; 1(3): 193-198.

14. Divya S, Ramesh $\mathrm{K}$ and Poornima N: Synthesis, Characterization of novel Benzimidazole derivatives. IJPBS 2012; 2(2): 143-149.

15. Kumar S, Subramanian M and Chinnaiyan S: Synthesis, Characterization and evaluation of N-mannich bases of 2substituted Benzimidazole derivatives. J Young pharm, 2013; 5(4): 154-159.

16. Akhtar S: Benzimidazole derivatives. International journal of scientific and engineering research 2013; 4: 1674.

17. Moein M, Moein S and Ahmadizadeh S: Radical Scavenging and Reducing Power of Salvia mirzayanii Subfractions. Molecules 2008; 13(11): 2804-2813.

18. Marinova, G: Evaluation of the methods for determination of the free radical scavenging activity by DPPH. Bulgarian journal of Agricultural Sciences 2011; 17(1): 11-24.

19. Chakkaravarthi K, Gokulakrishnan K, Suman T and Tamil Vendan D: Synthesize spectral, antimicrobial and antioxidant studies of diamide Mannich base derivatives. International journal of pharmacy and pharmaceutical sciences 2014; 6(1): 492-495.

20. Leonard JT, Jeyaseeli L, Kumar M and Sivakumar R: 'Synthesis, anti- inflammatory and antibacterial activities of 4-substituted phenyl benzimidazoles', Asian J. Chem., 2006; 18: 1104-1106.

21. Srinivasan N, Balaji A, Nagrajan G, Suthakaran R, Kumar $\mathrm{Y}$ and Jagdesh D: 'Synthesis and biological screening of some new 3 (2-methyl-1, 2- dihydropyrimido [1,2-c] benzimidazole-1-thionyl)-6,8-dibromo-2-substituted - 3Hqunazolin-4-one', Asian J. Chem. 2008; 20: 4934-4936.
22. Ansari KF and Lal C: 'Synthesis and evaluation of some new benzimidazole derivatives as potential antimicrobial agents', Eur. J. Med. Chem. 2009; 44: 2294-2299.

23. Alonso FP and Cook HJ: 'Synthesis and in vitro cysticidal activity of new benzimidazole derivatives', Eur. J. Med. Chem. 2009; 44: 1794-1800.

24. Kazimierczuk Z, Andrzejewska M, Kaustova J and Klimesova V: 'Synthesis and antimycobacterial activity of 2-substituted halogeno- benzimidazoles', Eur. J. Med. Chem. 2005; 40: 203-220.

25. Dutra AL, Arienti KL and Buzard DJ: 'Identification of 2arylbenzimidazoles as potent human histamine $\mathrm{H} 4$ receptor ligands', Bioorg. Med. Chem. Lett. 2006; 16: 6043-6048.

26. Sondhi SM, Singh S, Kumar A, Lozach O and Meijer L: 'Synthesis, anti - inflammatory, analgesic and kinase inhibition activity evaluation of benzimidazole derivatives', Bioorg. Med. Chem. 2006; 14: 3758-3765.

27. Santosh P, Pandeya S and Pathak A: Benzimidazole: A Versatile Chemical Entity. IJRAP 2011; 2(6): 1726-1737.

28. Divya S, Ramesh $\mathrm{K}$ and Poornima N: Synthesis, Characterization of novel Benzimidazole derivatives. IJPBS 2012; 2(2): 143-149.

29. Misbah R and Muhammad I: Mannich base derivatives of Benzimidazole: Synthesis, Antimicrobial properties. WAP3 2013; 558-564.

30. Verma A, Singh A, Nagaraju B and Sharma M: Synthesis, Characterization, Antimicrobial, Analgesic and Antiinflammatory activity of novel Mannich bases of Benzimidazole. World Journal of Pharmaceutical Research 2014; 3(4): 517-528.

31. Akhtar S: Benzimidazole derivatives. International journal of scientific and engineering research 2013; 4: 1674.

32. Leonard JT, Jeyaseeli L, Kumar M and Sivakumar R: 'Synthesis, anti- inflammatory and antibacterial activities of 4-substituted phenyl benzimidazoles', Asian J. Chem., 2006; 18: 1104-1106.

33. Ansari KF and Lal C: 'Synthesis and evaluation of some new Benz imidazole derivatives as potential antimicrobial agents', Eur. J. Med. Chem. 2009; 44: 2294-2299.

34. Alagoz ZA, Kus $\mathrm{C}$ and Coban T: 'Synthesis and antioxidant properties of novel benzimidazoles containing substituted indoles', J. Enz. Inhib. Med. Chem. 2004; 20: 325-331.

\section{How to cite this article:}

Anand K and Wakode S: Synthesis, characterization and biological evaluation of benzimidazole derivatives. Int J Pharm Sci \& Res 2018 ; 9(2): 617-24. doi: 10.13040/IJPSR.0975-8232.9(2).617-24.

All @ 2013 are reserved by International Journal of Pharmaceutical Sciences and Research. This Journal licensed under a Creative Commons Attribution-NonCommercial-ShareAlike 3.0 Unported License.

This article can be downloaded to ANDROID OS based mobile. Scan QR Code using Code/Bar Scanner from your mobile. (Scanners are available on Google Playstore) 